\title{
Dirac Semimetals in Homogeneous Holey Carbon Nitride Monolayers
}

\author{
Rui Tan, ${ }^{1}$ Zehou Li, ${ }^{1}$ Pan Zhou, ${ }^{2,}{ }^{*}$ Zhengchun Zou, ${ }^{1}$ Wenqi Li, ${ }^{1}$ and Lizhong Sun ${ }^{1,} \dagger$ \\ ${ }^{1}$ Hunan Provincial Key laboratory of Thin Film Materials and Devices, \\ School of Material Sciences and Engineering, Xiangtan University, Xiangtan 411105, China \\ ${ }^{2}$ School of Material Sciences and Engineering, Xiangtan University, Xiangtan 411105, China \\ (Dated: March 2, 2021)
}

\section{Contents:}

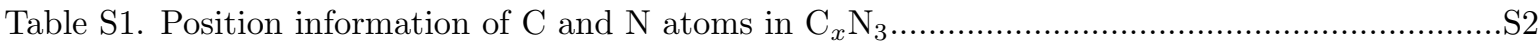

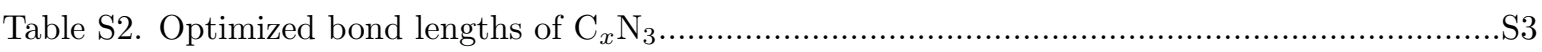

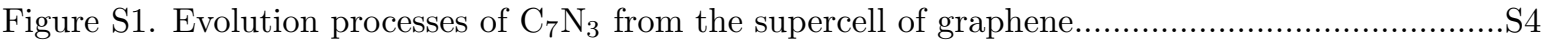

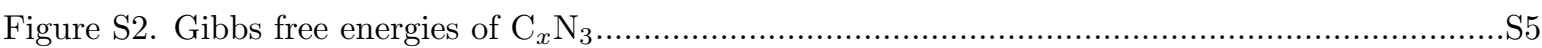

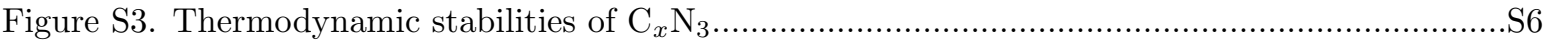

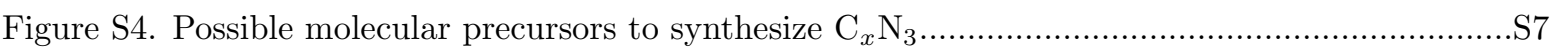

Figure S5. Band structures calculated by HSE06 hybrid functional.....................................S 8

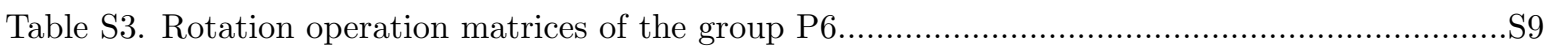

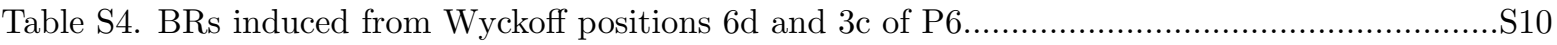

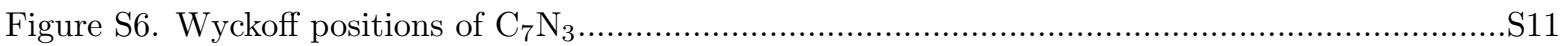

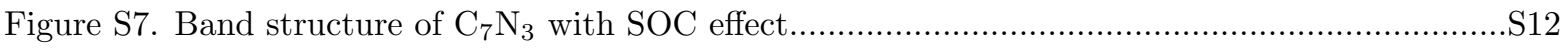

Figure S8. Band structures of $\mathrm{C}_{7} \mathrm{~N}_{3}$ under different biaxial strains.....................................S13 


\section{THE POSITION INFORMATION OF $\mathrm{C}_{x} \mathrm{~N}_{3}$ MONOLAYERS.}

The crystallographic inequivalent atomic positions information of these four carbon nitride monolayers $\mathrm{C}_{x} \mathrm{~N}_{3}(x=$ $7,10,13,19)$ are presented in Table $\mathrm{S} 1$. There are three kinds of inequivalent $\mathrm{C}$ atoms in $\mathrm{C}_{7} \mathrm{~N}_{3}$ and $\mathrm{C}_{10} \mathrm{~N}_{3}$, while the inequivalent numbers of $\mathrm{C}$ atoms become five kinds in $\mathrm{C}_{13} \mathrm{~N}_{3}$ and $\mathrm{C}_{19} \mathrm{~N}_{3}$. All of the $\mathrm{N}$ atoms in $\mathrm{C}_{x} \mathrm{~N}_{3}(x=7,10,13$, 19) are equivalent.

Table S1: Position information of the inequivalent $\mathrm{C}$ atoms and all equivalent $\mathrm{N}$ atoms in $\mathrm{C}_{7} \mathrm{~N}_{3}, \mathrm{C}_{10} \mathrm{~N}_{3}, \mathrm{C}_{13} \mathrm{~N}_{3}$ and $\mathrm{C}_{19} \mathrm{~N}_{3}$.

\begin{tabular}{|c|c|c|c|c|c|}
\hline Carbon nitride & $\mathrm{C}(\mathrm{N})$ & Wyckoff position & $\mathrm{X}$ & $\mathrm{Y}$ & Z \\
\hline & $\mathrm{C} 1$ & $6 \mathrm{~d}$ & 0.7272 & 0.2085 & 0.5000 \\
\hline \multirow[t]{4}{*}{$\mathrm{C}_{7} \mathrm{~N}_{3}$} & $\mathrm{C} 2$ & $6 \mathrm{~d}$ & 0.5713 & 0.5924 & 0.5000 \\
\hline & C3 & $2 \mathrm{~b}$ & 0.3333 & 0.6667 & 0.5000 \\
\hline & $\mathrm{N}$ & $6 \mathrm{~d}$ & 0.2561 & 0.3562 & 0.5000 \\
\hline & $\mathrm{C} 1$ & $12 f$ & 0.6743 & 0.0870 & 0.5000 \\
\hline \multirow[t]{5}{*}{$\mathrm{C}_{10} \mathrm{~N}_{3}$} & $\mathrm{C} 2$ & $6 e$ & 0.1653 & 0.5827 & 0.5000 \\
\hline & C3 & $2 \mathrm{~b}$ & 0.6667 & 0.3333 & 0.5000 \\
\hline & $\mathrm{N}$ & $6 e$ & 0.8337 & 0.1663 & 0.5000 \\
\hline & $\mathrm{C} 1$ & $6 \mathrm{~d}$ & 0.5624 & 0.4926 & 0.5000 \\
\hline & $\mathrm{C} 2$ & $6 \mathrm{~d}$ & 0.7712 & 0.1681 & 0.5000 \\
\hline \multirow[t]{6}{*}{$\mathrm{C}_{13} \mathrm{~N}_{3}$} & C3 & $6 \mathrm{~d}$ & 0.2962 & 0.3783 & 0.5000 \\
\hline & $\mathrm{C} 4$ & $6 \mathrm{~d}$ & 0.3502 & 0.8078 & 0.5000 \\
\hline & C5 & $2 \mathrm{~b}$ & 0.6667 & 0.3333 & 0.5000 \\
\hline & $\mathrm{N}$ & $6 \mathrm{~d}$ & 0.0344 & 0.2788 & 0.5000 \\
\hline & $\mathrm{C} 1$ & $6 e$ & 0.5333 & 0.4666 & 0.5000 \\
\hline & $\mathrm{C} 2$ & $12 \mathrm{f}$ & 0.6676 & 0.5351 & 0.5000 \\
\hline \multirow[t]{4}{*}{$\mathrm{C}_{19} \mathrm{~N}_{3}$} & C3 & $12 f$ & 0.6707 & 0.7403 & 0.5000 \\
\hline & $\mathrm{C} 4$ & $6 e$ & 0.7337 & 0.4674 & 0.5000 \\
\hline & C5 & $2 \mathrm{~b}$ & 0.3333 & 0.6667 & 0.5000 \\
\hline & $\mathrm{N}$ & $6 e$ & 0.8671 & 0.7342 & 0.5000 \\
\hline
\end{tabular}




\section{THE OPTIMIZED BOND LENGTHS OF $\mathrm{C}_{x} \mathbf{N}_{3}$ MONOLAYERS.}

The optimized bond lengths of these four carbon nitride monolayers $\mathrm{C}_{x} \mathrm{~N}_{3}(x=7,10,13,19)$ are presented in Table $\mathrm{S} 2$. The bond lengths between all $\mathrm{C}$ toms are in the range of $1.41-1.47 \AA$ in the four carbon nitride monolayers, which are similar to graphene (1.42 $\AA$, a typical bond length for $s p^{2} \mathrm{C}-\mathrm{C}$ bonds). There are two different lengths between $\mathrm{C}$ and $\mathrm{N}$ atoms in $\mathrm{C}_{x} \mathrm{~N}_{3}$, which have almost the same value with g- $\mathrm{C}_{3} \mathrm{~N}_{4}(\sim 1.33 \AA)$ and $\mathrm{C}_{2} \mathrm{~N}(1.33 \AA)$. Overall, the $\mathrm{C}_{x} \mathrm{~N}_{3}$ monolayers belong to stable holey $2 \mathrm{D}$ structures with $s p^{2}$ hybridization bonds.

Table S2: The optimized bond lengths $(\AA)$ of $\mathrm{C}_{7} \mathrm{~N}_{3}, \mathrm{C}_{10} \mathrm{~N}_{3}, \mathrm{C}_{13} \mathrm{~N}_{3}$ and $\mathrm{C}_{19} \mathrm{~N}_{3}$.

\begin{tabular}{ccccc}
\hline bonds & $\mathrm{C}_{7} \mathrm{~N}_{3}$ & $\mathrm{C}_{10} \mathrm{~N}_{3}$ & $\mathrm{C}_{13} \mathrm{~N}_{3}$ & $\mathrm{C}_{19} \mathrm{~N}_{3}$ \\
\hline $\mathrm{C}_{1}-\mathrm{C}_{1}$ & - & 1.46 & 1.41 & 1.41 \\
$\mathrm{C}_{1}-\mathrm{C}_{2}$ & 1.45 & 1.43 & - & 1.42 \\
$\mathrm{C}_{1}-\mathrm{C}_{3}$ & 1.42 & - & 1.44 & - \\
$\mathrm{C}_{1}-\mathrm{C}_{4}$ & - & - & 1.42 & - \\
$\mathrm{C}_{2}-\mathrm{C}_{2}$ & 1.45 & - & - & - \\
$\mathrm{C}_{2}-\mathrm{C}_{3}$ & - & 1.41 & 1.47 & 1.44 \\
$\mathrm{C}_{2}-\mathrm{C}_{4}$ & - & - & 1.43 & 1.42 \\
$\mathrm{C}_{3}-\mathrm{C}_{3}$ & - & - & - & 1.47 \\
$\mathrm{C}_{4}-\mathrm{C}_{5}$ & - & - & 1.42 & 1.42 \\
$\mathrm{~N}-\mathrm{C}_{1}$ & 1.34 & 1.34 & - & - \\
$\mathrm{N}_{-}-\mathrm{C}_{2}$ & 1.33 & - & 1.34 & - \\
$\mathrm{N}_{-}-\mathrm{C}_{3}$ & - & - & 1.34 & 1.34 \\
\hline & & & & \\
\hline
\end{tabular}


The $\mathrm{C}_{7} \mathrm{~N}_{3}$ monolayer can be constructed from the $\sqrt{13} \times \sqrt{13}$ supercell of graphene. Firstly, a six-membered ring of graphene need to be removed to obtain the hole, and then replace the carbon atoms which locate at the edge of the hole by nitrogen atoms.

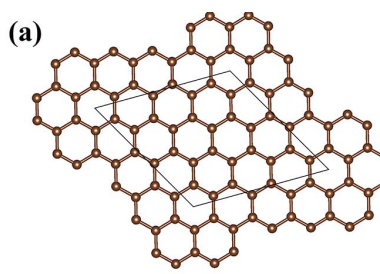

$\sqrt{13} \times \sqrt{13}$ supercell of graphene

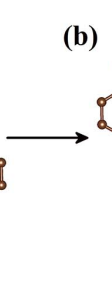

(b)

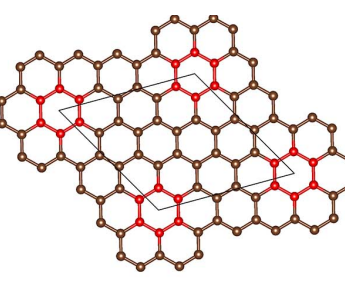

mark four $\mathrm{C}$ rings to be removed (c)

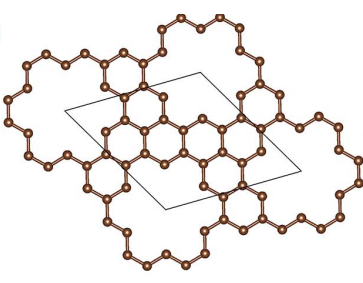

remove four 6-membered $\mathrm{C}$ rings

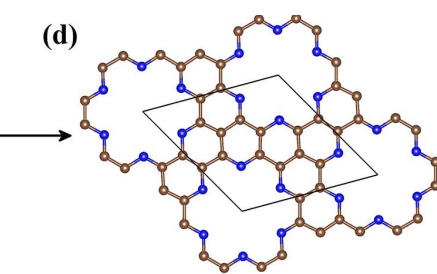

replace edge $C$ with $N$ atoms

Figure S1: The evolution processes of $\mathrm{C}_{7} \mathrm{~N}_{3}$ monolayer from the $\sqrt{13} \times \sqrt{13}$ supercell of graphene. 


\section{THE GIBBS FREE ENERGIES OF $\mathrm{C}_{x} \mathrm{~N}_{3}$ MONOLAYERS.}

Here we compare the Gibbs free energies of $\mathrm{C}_{x} \mathrm{~N}_{3}(x=7,10,13,19)$ with the already-synthesized 2D carbon nitride materials ( $\mathrm{g}-\mathrm{CN}, \mathrm{C}_{2} \mathrm{~N}, \mathrm{C}_{3} \mathrm{~N}$ and $\mathrm{g}_{-} \mathrm{C}_{3} \mathrm{~N}_{4}$ ). The results shown that the calculated Gibbs free energies of the 2D carbon nitrides are all positive, which corresponding to the non-spontaneous formation process. Comparing with these already-synthesized 2D carbon nitride materials, the proposed four carbon nitrides have rather lower Gibbs free energies, indicating the easier synthesized to some extent. Moreover, the Gibbs free energies decrease with the increase of $\mathrm{C}$ atoms in the proposed four $\mathrm{C}_{x} \mathrm{~N}_{3}$ materials.

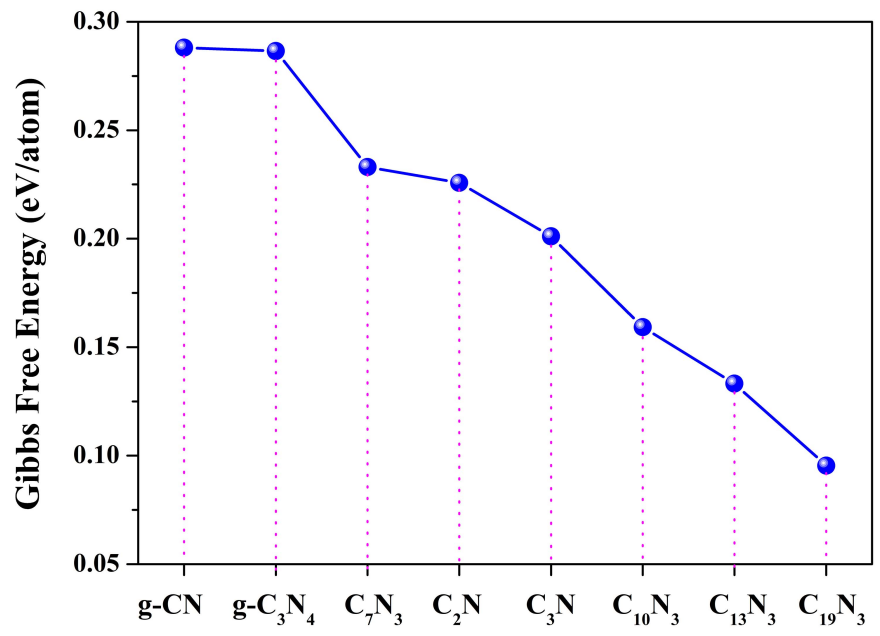

Figure S2: The calculated Gibbs free energies of $\mathrm{C}_{7} \mathrm{~N}_{3}, \mathrm{C}_{10} \mathrm{~N}_{3}, \mathrm{C}_{13} \mathrm{~N}_{3}$ and $\mathrm{C}_{19} \mathrm{~N}_{3}$ compared with g- $\mathrm{C}_{3} \mathrm{~N}_{4}, \mathrm{~g}-\mathrm{CN}, \mathrm{C}_{2} \mathrm{~N}$ and $\mathrm{C}_{3} \mathrm{~N}$. 


\section{THE AB INITIO MOLECULAR DYNAMICS (AIMD) SIMULATIONS FOR C N $_{3}$ MONOLAYERS.}

The thermal stabilities of these four carbon nitride monolayers $\mathrm{C}_{x} \mathrm{~N}_{3}(x=7,10,13,19)$ have been examined by performing the ab initio molecular dynamics (AIMD) simulations. As shown in Figure S3, we plot the snapshots of atomic configuration after NVT simulations and energy changes during the process of AIMD simulations, which are arried out using a $2 \times 2$ supercell at temperature of $300 \mathrm{~K}$. In each case, the simulation is last for 6 ps with a time step of 1 fs. The snapshots show that the geometries of four carbon nitride monolayers are well-preserved and no structural breakage are occurred, indicating the strong thermal stabilities of these four $\mathrm{C}_{x} \mathrm{~N}_{3}$ monolayers at room temperature.
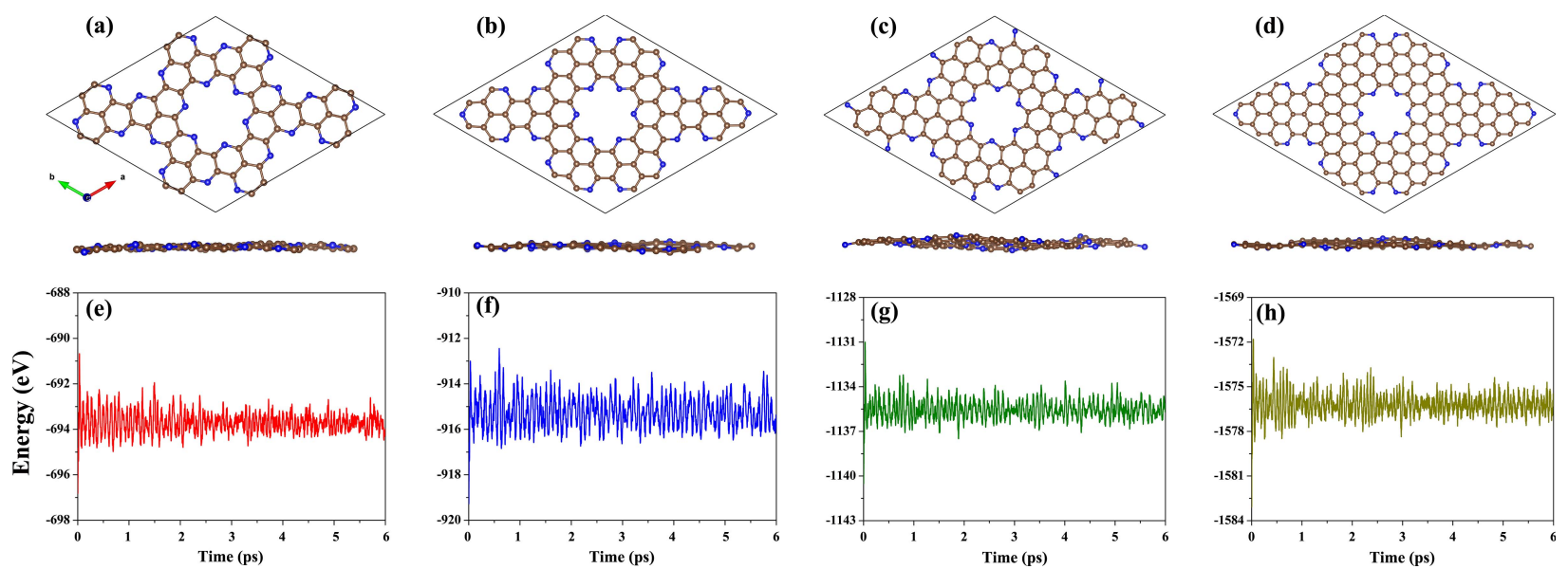

Figure S3: The snapshots of (a) $\mathrm{C}_{7} \mathrm{~N}_{3}$, (b) $\mathrm{C}_{10} \mathrm{~N}_{3}$, (c) $\mathrm{C}_{13} \mathrm{~N}_{3}$ and (d) $\mathrm{C}_{19} \mathrm{~N}_{3}$ monolayers at the end of AIMD simulations under $300 \mathrm{~K}$. (e)-(f) are the corresponding total energy fluctuations with times under $300 \mathrm{~K}$. 
(a)

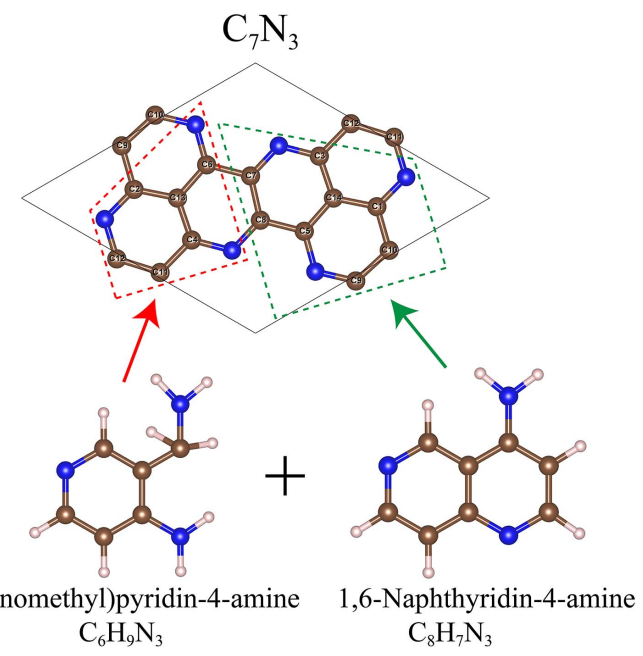

(c)

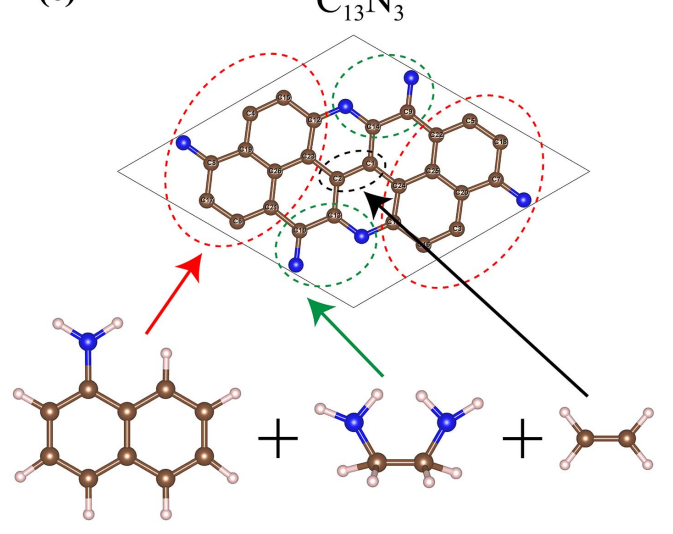

1-Naphthylamine $\mathrm{C}_{10} \mathrm{H}_{9} \mathrm{~N}$
Ethylenediamine $\mathrm{C}_{2} \mathrm{H}_{8} \mathrm{~N}_{2}$
$\mathrm{C}_{2} \mathrm{H}_{4}$ (b)
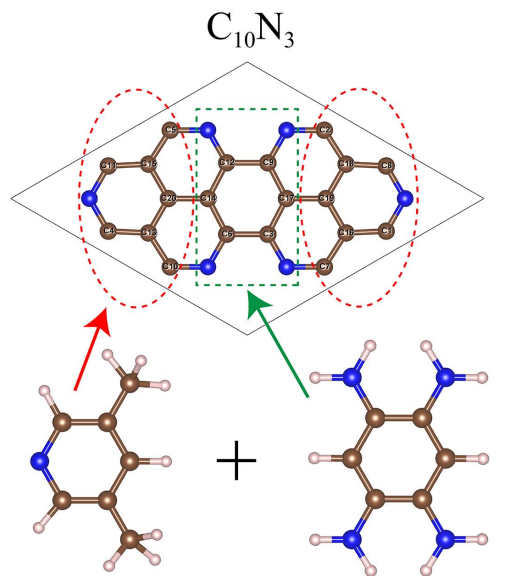

3,5-Dimethylpyridin 1,2,4,5-Benzenetetramine $\mathrm{C}_{7} \mathrm{H}_{9} \mathrm{~N}$
$\mathrm{C}_{6} \mathrm{H}_{10} \mathrm{~N}_{4}$

(d)

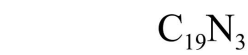

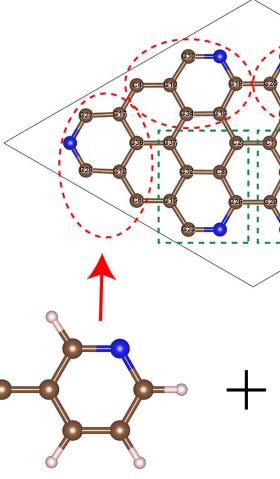

3-Methylpyridine $\mathrm{C}_{6} \mathrm{H}_{7} \mathrm{~N}$

Figure S4: Schematic presentations of the appropriate molecular precursors to synthesize (a) $\mathrm{C}_{7} \mathrm{~N}_{3}$, (b) $\mathrm{C}_{10} \mathrm{~N}_{3}$, (c) $\mathrm{C}_{13} \mathrm{~N}_{3}$ and (d) $\mathrm{C}_{19} \mathrm{~N}_{3}$ monolayers. The brown, blue and pink spheres represent $\mathrm{C}, \mathrm{N}$ and $\mathrm{H}$ atoms, respectively. 


\section{THE BAND STRUCTURES CALCULATED BY THE HSE06 HYBRID FUNCTIONAL.}

The band structures of these four carbon nitride monolayers $\mathrm{C}_{x} \mathrm{~N}_{3}(x=7,10,13,19)$ are also calculated by using the HSE06 hybrid functional due to the band-gap is generally underestimated in PBE functional. Clearly, the Dirac cone is still well preserved, suggesting the trustworthy results from PBE functional.
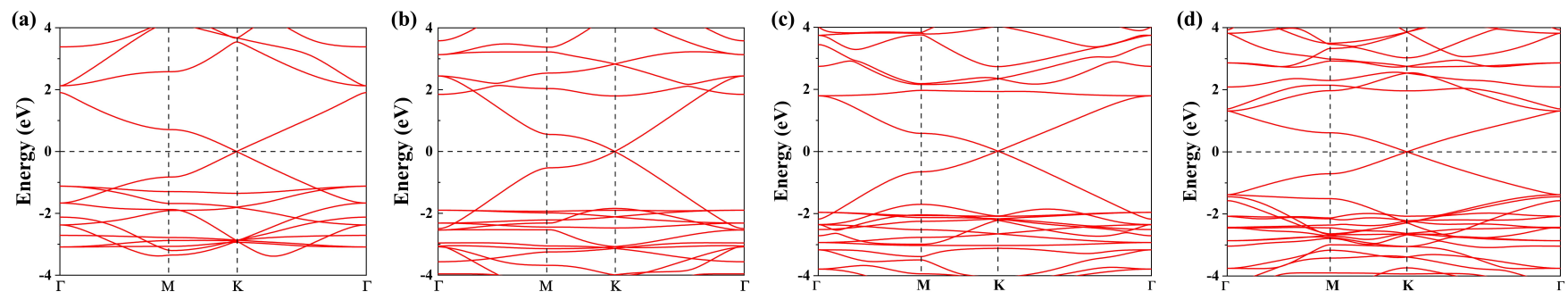

Figure S5: The band structures of (a) $\mathrm{C}_{7} \mathrm{~N}_{3}$, (b) $\mathrm{C}_{10} \mathrm{~N}_{3}$, (c) $\mathrm{C}_{13} \mathrm{~N}_{3}$ and (d) $\mathrm{C}_{19} \mathrm{~N}_{3}$ monolayers calculated by HSE06 hybrid functional, respectively. 
VIII. ROTATION OPERATION MATRICES OF THE GROUP P6 (NO. 168)

The matrix representations of the rotation symmetry operators in space group $P 6$ are presented.

\begin{tabular}{|c|c|c|}
\hline No. & Matrix form & Seitz label \\
\hline 1 & $\left(\begin{array}{lllll}1 & 0 & 0 & & 0 \\
0 & 1 & 0 & & 0 \\
0 & 0 & 1 & & 0\end{array}\right)$ & $\{E \mid 0\}$ \\
\hline 2 & $\left(\begin{array}{cccc}0 & -1 & 0 & 0 \\
1 & -1 & 0 & 0 \\
0 & 0 & 1 & 0\end{array}\right)$ & $\left\{C_{3 z}^{+} \mid 0\right\}$ \\
\hline 3 & $\left(\begin{array}{ccccc}-1 & 1 & 0 & 0 \\
-1 & 0 & 0 & 0 \\
0 & 0 & 1 & 0\end{array}\right)$ & $\left\{C_{3 z}^{-} \mid 0\right\}$ \\
\hline 4 & $\left.\begin{array}{cccc}-1 & 0 & 0 & 0 \\
0 & -1 & 0 & 0 \\
0 & 0 & 1 & 0\end{array}\right)$ & $\left\{C_{2 z} \mid 0\right\}$ \\
\hline 5 & $\left(\begin{array}{cccc}0 & 1 & 0 & 0 \\
-1 & 1 & 0 & 0 \\
0 & 0 & 1 & 0\end{array}\right)$ & $\left\{C_{6 z}^{-} \mid 0\right\}$ \\
\hline 6 & $\left(\begin{array}{cccc}1 & -1 & 0 & 0 \\
1 & 0 & 0 & 0 \\
0 & 0 & 1 & 0\end{array}\right)$ & $\left\{C_{6 z}^{+} \mid 0\right\}$ \\
\hline
\end{tabular}


IX. BRS INDUCCED FROM WYCKOFF POSITIONS 6D AND 3C OF P6

Table S4: BRs inducced from Wyckoff positions $6 \mathrm{~d}$ and $3 \mathrm{c}$ of $P 6$.

\begin{tabular}{cccccc}
\hline \hline$W P$ & $\rho$ & $\Gamma$ & $M$ & $K$ & Dim. \\
\hline $6 d\left(C_{1}\right)$ & $A$ & $\Gamma_{1} \oplus \Gamma_{2} \bigoplus \Gamma_{3} \Gamma_{5} \oplus \Gamma_{4} \Gamma_{6}$ & $3 M_{1} \oplus 3 M_{2}$ & $2 K_{1} \oplus 2 K_{2} K_{3}$ & 6 \\
\hline $3 c\left(C_{2}\right)$ & $A$ & $\Gamma_{1} \oplus \Gamma_{3} \Gamma_{5}$ & $M_{1} \oplus 2 M_{2}$ & $K_{1} \oplus K_{2} K_{3}$ & 3 \\
& $B$ & $\Gamma_{2} \oplus \Gamma_{4} \Gamma_{6}$ & $2 M_{1} \oplus M_{2}$ & $K_{1} \oplus K_{2} K_{3}$ & 3 \\
\hline \hline
\end{tabular}


X. WYCKOFF POSITIONS OF $\mathrm{C}_{7} \mathrm{~N}_{3}$.

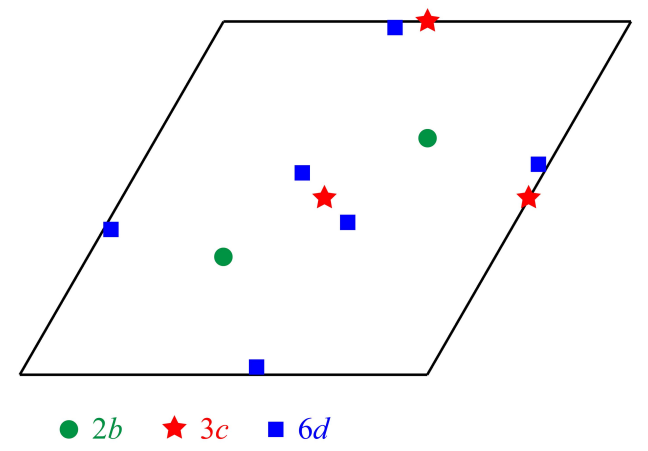

Figure S6: The Wyckoff positions of $\mathrm{C}_{7} \mathrm{~N}_{3}$ monolayer. 


\section{BAND STRUCTURE OF $\mathrm{C}_{7} \mathrm{~N}_{3}$ WITH SOC.}

Here, we further examine the spin-orbit coupling (SOC) effect on the electronic structure of the proposed carbon nitride. As shown in Figure S7, it is found that the SOC induced gap size is very tiny, which can be attributed to both $\mathrm{C}$ and $\mathrm{N}$ are light elements and the SOC effect is rather weak.

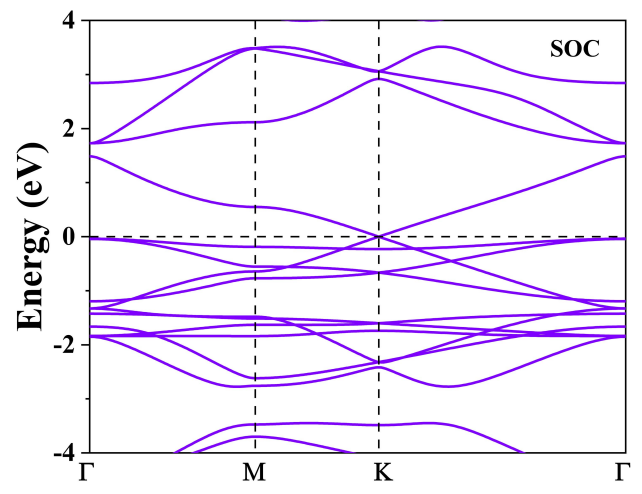

Figure S7: The band structure of $\mathrm{C}_{7} \mathrm{~N}_{3}$ monolayer calculated by PBE functional with SOC considered. 


\section{THE BAND STRUCTURE OF $\mathrm{C}_{7} \mathrm{~N}_{3}$ UNDER DIFFERENT BIAXIAL STRAINS.}

To further confirm the robustness of Dirac cone in the proposed carbon nitride monolayers, a series of biaxial strains are exerted on the $\mathrm{C}_{7} \mathrm{~N}_{3}$ monolayer. It can be seen that under such strong tensile strains (6\%), the Dirac cone remains at the high-symmetry $K$ point near the Fermi level, showing the robustness of Dirac cone under external strain.
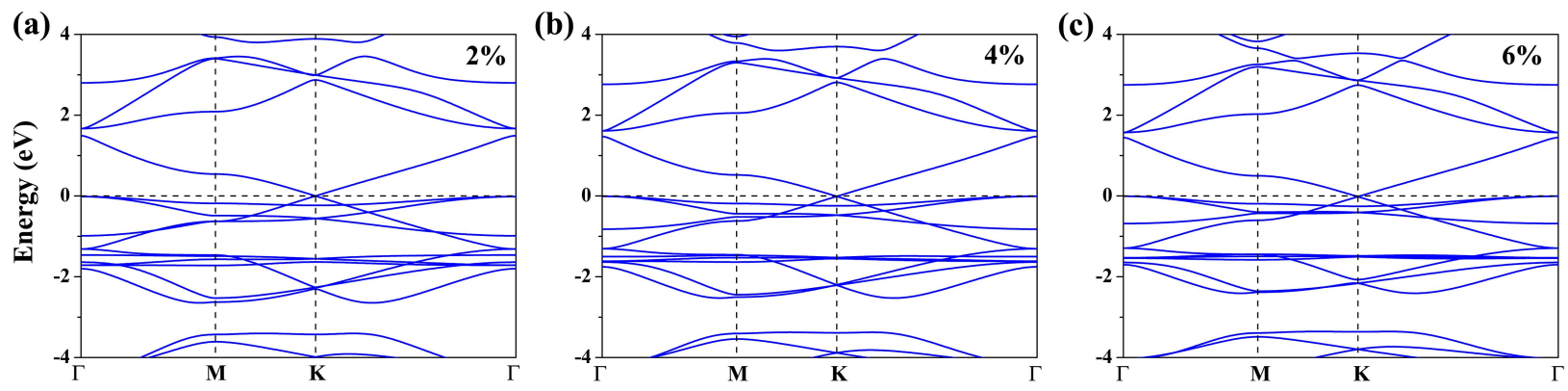

Figure S8: The band structures of $\mathrm{C}_{7} \mathrm{~N}_{3}$ monolayer under mild tensile biaxial strains.

* Electronic address: zhoupan71234@xtu.edu.cn

$\dagger$ Electronic address: lzsun@xtu.edu.cn 